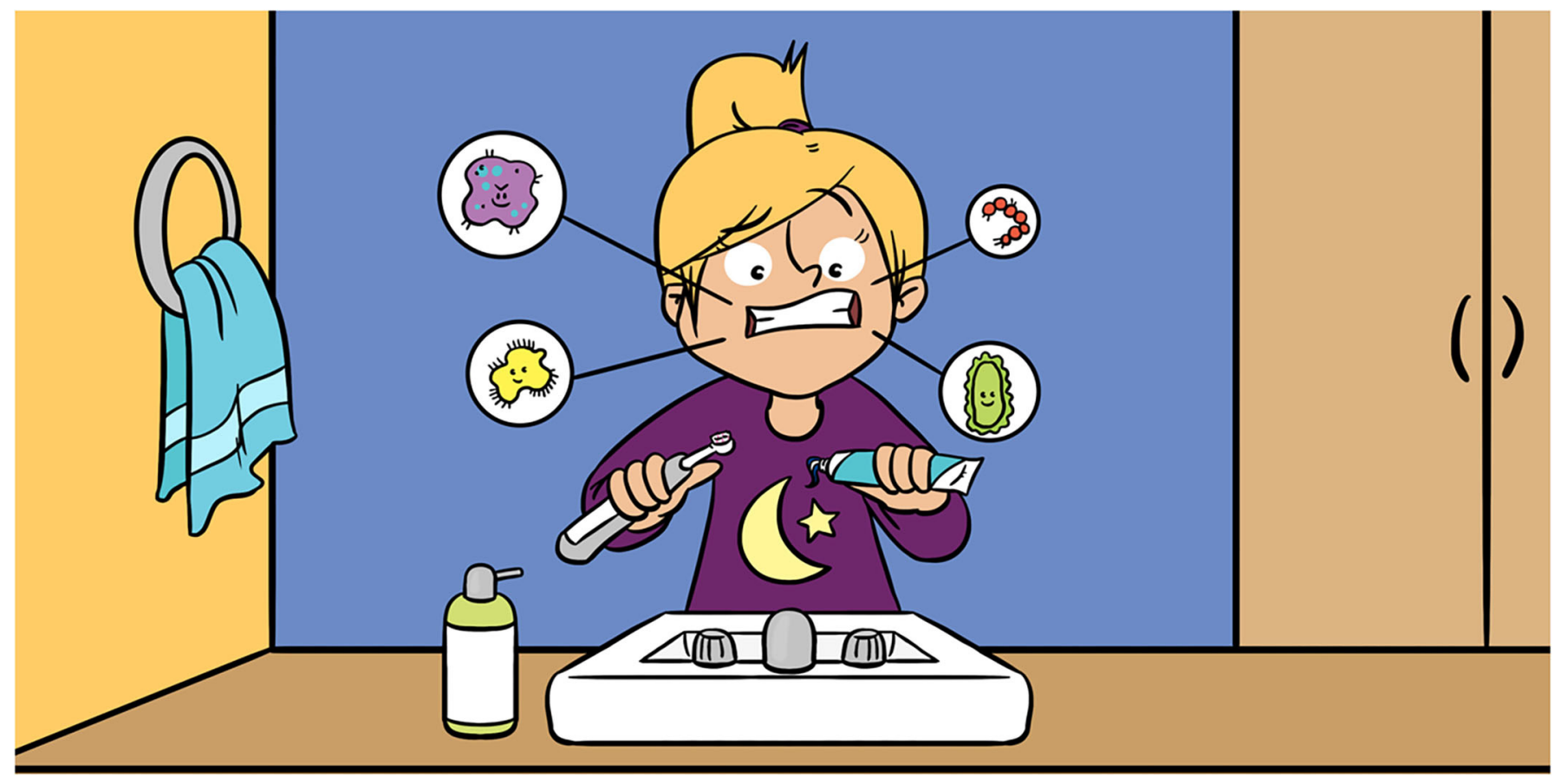

\title{
THE MILLIONS OF MICROBIAL REASONS YOU NEED TO BRUSH YOUR TEETH
}

\author{
Abigail Shahar Gancz ${ }^{1 *}$, Sterling Wright ${ }^{1}$, Nicole E. Moore ${ }^{1}$ and Laura S. Weyrich ${ }^{1,2}$ \\ ${ }^{1}$ The Pennsylvania State University (PSU), State College, PA, United States \\ ${ }^{2}$ Australian Centre for Ancient DNA, University of Adelaide, Adelaide, SA, Australia
}

\section{YOUNG REVIEWERS:}

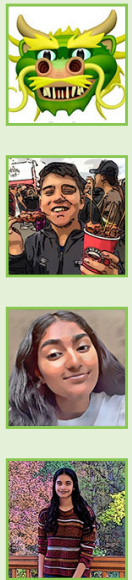
GUS

AGE: 13

NAYAN

AGE: 13

SANDHYA

AGE: 15

SANJANA

AGE: 14

Millions of tiny critters called microorganisms live in your mouth.

Each one is unique and has a specific job. For instance, some microorganisms help with digesting food and others protect you from dangerous infections. Some microorganisms come from your parents, some from the foods you eat, and some from not brushing your teeth. All these microorganisms need food. The good microorganisms that help your mouth stay healthy enjoy eating vegetables, fruits, and grains; the bad ones like sugar. When you eat too much sugar, the bad microorganisms can cause painful problems in your mouth. They may even cause you to lose your teeth or make your gums bleed. Fortunately, brushing your teeth helps remove these rogue bacteria. While we know some things about the microorganisms in the mouth, there is still much we do not know and are still working to discover. 
Figure 1

The oral microbiome in dental plaque. Many types of microorganisms work together to form complex communities in different parts of the mouth. Dental plaque, the sticky film of microorganisms living on the surfaces of teeth (yellow), is incredibly complex, and the way these microorganisms work together is still being researched today.

\section{MICROORGANISM}

A living organism that is too small to see without a microscope. Microorganisms include bacteria, archaea, viruses, fungi, yeasts, and parasites.

\section{MICROBIOME}

All the microorganisms living in a particular area, along with the proteins or chemicals that make that area unique.

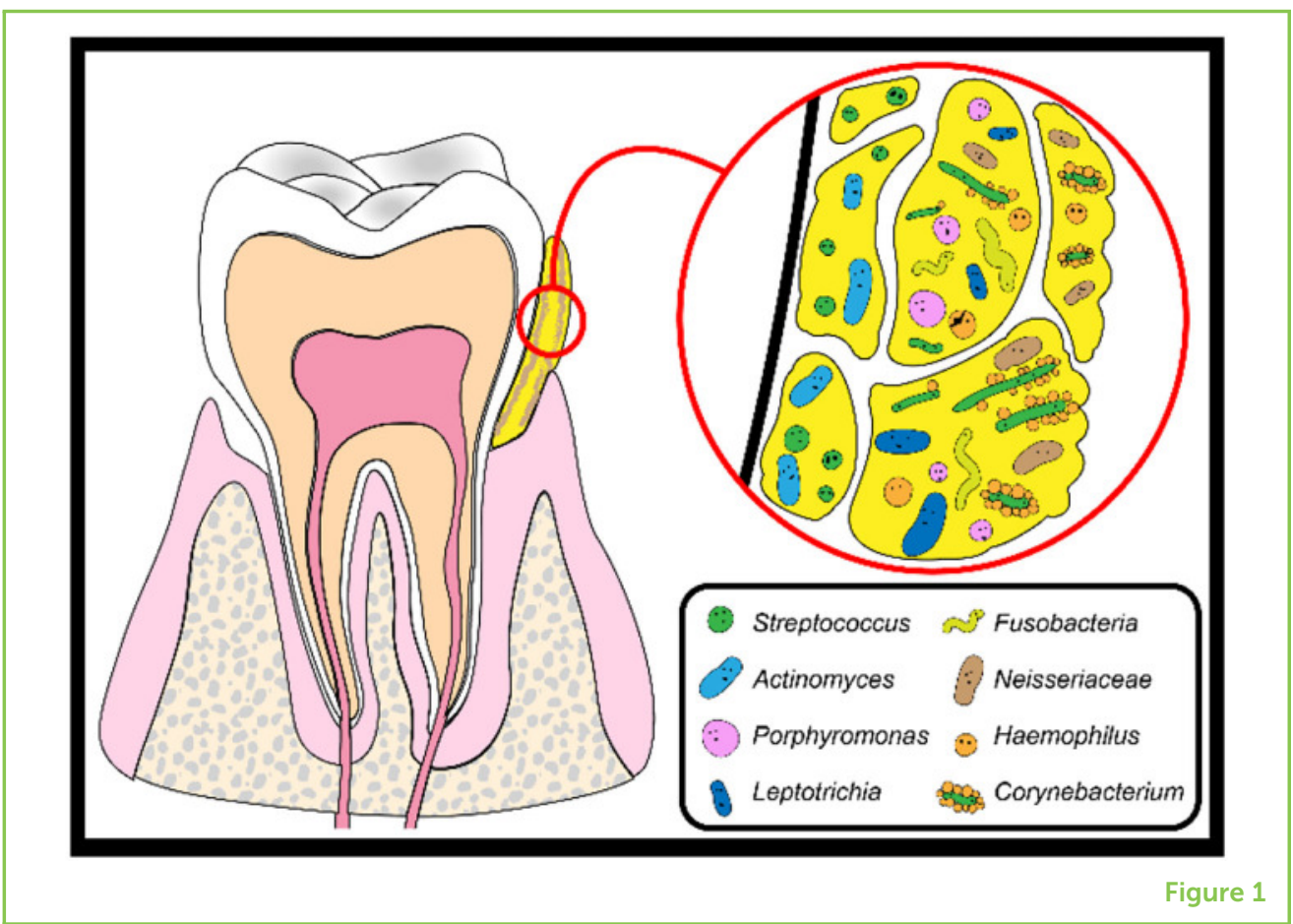

\section{THERE ARE TINY CREATURES LIVING IN YOUR MOUTH}

Millions of tiny, nearly invisible creatures live in your mouth. Scientists refer to these creatures as microorganisms. They crawl around your tongue, live on your teeth, and look for food at the top of your mouth. Right now, there are over 200 distinct species (types) of microorganisms in your mouth! These tiny critters come in nearly infinite shapes and sizes, including some that are shaped like spiral noodles, basketballs, hot dogs, and even small robots (Figure 1). Some have tails called flagella that they use to move around, while others extrude glue-like slime to make sure they and their friends can stick to surfaces. This world is incredibly tiny-each microorganism is over 100 times smaller than one of your cells and is even tinier than the end of a pin. This world, much like the human town or city where you live, is a community; each microorganism has a specific job to do. These communities are referred to by scientists as microbiomes-collections of different types of microorganisms, including bacteria, primitive bacteria called archaea, viruses, fungi, yeasts, and parasites, that all cooperate and live together in a certain place.

\section{HOW DID THESE MICROORGANISMS GET IN YOUR MOUTH?}

Your oral (mouth) microbiome is incredibly complex and changes throughout your life. If we continue to imagine microbiomes as human cities, distinct neighborhoods exist on your tongue, teeth, cheeks, gums, and even in your saliva. These neighborhoods are built slowly over time, as different microorganisms arrive in your mouth after 
ENAMEL

Enamel is the shiny, hard outer surface of teeth that helps to protect them against decay.

\section{CAVITY}

A damaged area in the enamel that is irreversible and can lead to more serious infections. Cavities are also called tooth decay or caries.

\section{GINGIVITIS}

The early stage of gum disease, which is reversible with better oral care. The gums are sometimes slightly red and tender.

\section{PERIODONTITIS}

A common, severe gum infection, also called gum disease, that damages gums and can cause tooth loss if untreated. Periodontitis is linked to stroke, diabetes, obesity, and heart disease.

PLAQUE

Dental plaque is a layer of microorganisms that build up on your teeth. Over time, it gives teeth a yellow or brown look. birth by catching rides on your food, hopping in from your mom's mouth, or slipping in on dust from the air. Early on, only specific types of microorganisms-let is call them the pioneers-are able to survive. However, once the pioneers settle in, they modify the environments of their neighborhoods in specific ways that allow other microorganisms to join them. Just as human pioneers once modified the wilderness so that towns could be built, a species of bacteria called Streptococcus constructs nice, sticky surfaces in the mouth that then allow other bacteria, such as Actinomyces, to adhere and take up residence [1].

\section{WHAT DO THESE MICROORGANISMS DO?}

Over time, different neighborhoods are filled with all kinds of microorganisms that perform diverse jobs that ensure the overall community functions properly [2]. Some microorganisms function as farmers, beginning the process of digestion and helping you get the maximum energy from your food (for e.g., Lactobacillus). Others are guardsmen, maintaining the barriers between you and your environment and keeping harmful chemicals, toxins, or even invading microorganisms from taking root (Streptococcus). Some even act as police to help keep dangerous microorganisms from causing infections and disease [3]. Researchers learn what these microorganisms are doing everyday by looking at what they produce (proteins) or the instructions they have to do certain tasks (DNA).

\section{WHEN MICROORGANISMS GO ROGUE...}

Many of our microorganism friends keep us healthy, but, when we eat a lot of sugar, forget to brush our teeth, or skip a visit to the dentist, some oral microorganisms can go rogue. For example, some bacteria love sweets, and, when given enough sugar, they begin to grow very quickly. In the process, they produce an acid that destroys a tooth's enamel (the hard, protective outer white surface of a tooth). This damage causes blackened holes, or cavities, in the teeth (Figure 2). Cavities can expose the nerves inside a tooth, causing pain. Without treatment, a cavity can allow other rogue bacteria to enter the tooth, and the tooth could become infected and may eventually even have to be removed.

Rogue bacteria can also cause other health problems in the mouth, such as gingivitis and periodontitis (Figure 2). Gingivitis occurs when rogue bacteria cause inflammation or bleeding of the gums. Gingivitis generally develops when bacteria grow in larger groups and form plaque between and around the teeth. Plaque can alter the immune system in the body to mistakenly attack the gums and cause accidental destruction of gum tissue. When left untreated, gingivitis can worsen and develop into periodontitis. Periodontitis is a severe gum infection 
Figure 2

Cavities, gingivitis, and periodontitis are all unpleasant mouth diseases that occur when microorganisms go rogue, either by breaking down teeth (cavities) or irritating and damaging the soft tissues of the mouth (gingivitis and periodontitis)

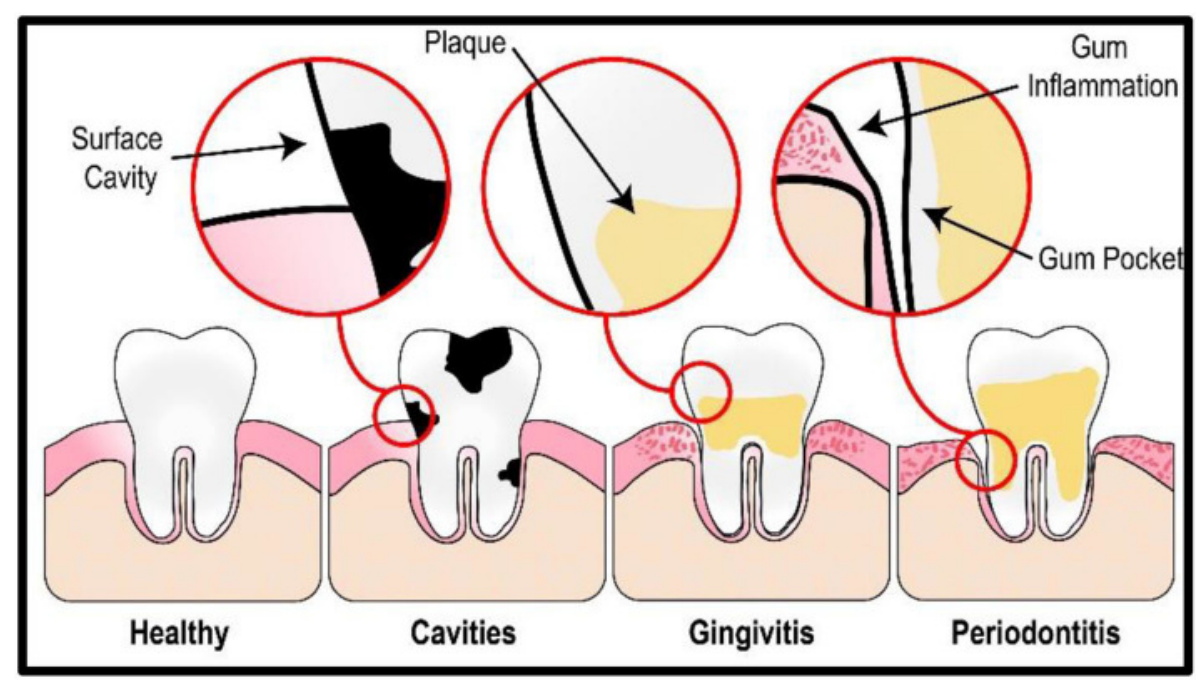

Figure 2

that may cause tooth loss and other illnesses. Teenagers are at a high risk for developing periodontitis, as puberty increases blood circulation to the gums and sensitivity to bacterial infections.

Along with cavities and periodontitis, oral bacteria can also contribute to other diseases outside of the mouth. Rogue oral bacteria can escape the mouth and travel to the gut, lungs, heart, and brain, or they can produce toxins and other nasty compounds that cause problems outside of the mouth. When oral microorganisms are in the wrong place, they can contribute to diseases such as colon cancer, heart and lung disease, arthritis, or even Alzheimer's disease. For instance, the rogue bacterium Porphyromonas gingivalis may contribute to Alzheimer's disease by producing toxins that travel from the mouth to the brain. All of these diseases illustrate that it is critical for everyone to take care of their mouths and reduce the number of rogue oral bacteria.

\section{DOES ANYONE ELSE SHARE YOUR ORAL MICROBIOME?}

If you eat the same foods as your friend, will both of you have the same oral microorganisms? Do you have the same microorganisms as your parents or siblings? The answer is complicated. Scientists have learned that a person's diet, ancestry, gender, place of birth, and oral hygiene play a role creating the oral microbiome [4] and that you share microbes with people in your family. For instance, the Batwa - a group of people who live in Uganda in Africa and hunt and gather their food-have more diverse oral microbiomes than other people who grow or buy their own food. We also know that the amount of fat, sugar, and coffee you consume can change the bacteria in your mouth. Researchers have also identified other factors, such as genetics and smoking, that encourage certain types of bacteria 
to live in the mouth. Although you have a completely unique oral microbiome, you share more microorganisms with people who live their lives the same way that you do. More research is needed to understand how environment, lifestyle, and ancestry work together to shape the oral microbiome.

\section{BRUSH YOUR TEETH!}

Current research suggests that regular brushing helps prevent rogue microorganisms from growing too much, invading other parts of your body, and causing harm. Brushing your teeth keeps the numbers of rogue bacteria low and promotes the general health of the body. While humans who lived thousands of years ago are thought to have had microbiomes with fewer rogue bacteria [5], major lifestyle changes in recent years have shifted the types of microorganisms living in our mouths, probably for the worse. Specifically, eating a lot of sugars and processed foods, and the use of antibiotics, may explain why people living today have higher numbers of rogue bacteria. Because these lifestyle choices are hard to overcome, you must brush your teeth with toothpaste to keep these rogue bacteria under control. Toothpaste also contains a mineral called fluoride, which strengthens the enamel on your teeth, creating additional armor to help protect teeth from rogue bacteria. Researchers hope that, 1 day, we will figure out how to encourage a healthier microbiome in our mouths, so that cavities will be a thing of the past!

\section{REFERENCES}

1. Welch, M. J. J., Rossetti, B. J., Rieken, C. W., Dewhirst, F. E., and Borisy, G. G. 2016. Biogeography of a microbiome at micron scale. Proc Natl Acad Sci USA. 113:E791-800. doi: 10.1073/pnas.1522149113

2. Kilian, M., Chapple, I. L. C., Hannig, M., Marsh, P. D., Meuric, V., Pedersen, A. M. L., et al. 2016. The oral microbiome-an update for oral healthcare professionals. $\mathrm{Br}$ Dent J. 221:657-66. doi: 10.1038/sj.bdj.2016.865

3. Doel, J. J., Hector, M. P., Amirtham, C. V., Al-Anzan, L. A., Benjamin, N., and Allaker, R. P. 2004. Protective effect of salivary nitrate and microbial nitrate reductase activity against caries. Euro J Oral Sci. 112:424-8. doi: 10.1111/j.1600-0722.2004.00153.x

4. Yang, Y., Zheng, W., Cai, Q., Shrubsole, M. J., Pei, Z., Brucker, R., et al. 2019. Racial differences in the oral microbiome: data from low-income populations of african ancestry and European ancestry. mSystems 4:e00639-19. doi: 10.1128/mSystems.00639-19

5. Adler, C. J., Dobney, K., Weyrich, L. S., Kaidonis, J., Walker, A. W., Haak, W., et al. 2013. Sequencing ancient calcified dental plaque shows changes in oral microbiota with dietary shifts of the neolithic and industrial revolutions. Nat Genet. 45:450-5.e1. doi: 10.1038/ng.2536 
SUBMITTED: 11 September 2020; ACCEPTED: 02 September 2021; PUBLISHED ONLINE: 15 October 2021.

EDITED BY: Vitor Engracia Valenti, São Paulo State University, Brazil

CITATION: Gancz AS, Wright S, Moore NE and Weyrich LS (2021) The Millions of Microbial Reasons You Need to Brush Your Teeth. Front. Young Minds 9:605224. doi: 10.3389/frym.2021.605224

CONFLICT OF INTEREST: The authors declare that the research was conducted in the absence of any commercial or financial relationships that could be construed as a potential conflict of interest.

COPYRIGHT @ 2021 Gancz, Wright, Moore and Weyrich. This is an open-access article distributed under the terms of the Creative Commons Attribution License (CC BY). The use, distribution or reproduction in other forums is permitted, provided the original author(s) and the copyright owner(s) are credited and that the original publication in this journal is cited, in accordance with accepted academic practice. No use, distribution or reproduction is permitted which does not comply with these terms.

\section{YOUNG REVIEWERS}

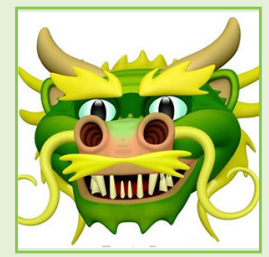

\section{GUS, AGE: 13}

I find how things work fascinating whether it is how the natural world functions or how man-made stuff works! If you really think about it how weird is it that things are not more chaotic?

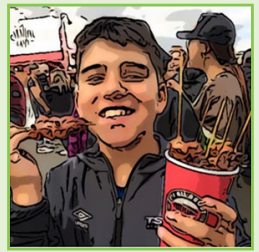

\section{NAYAN, AGE: 13}

My name is Nayan and I really like to play soccer. I also like to go rowing in racing boats. For fun, I fly remote control airplanes and drones. For exercise, I like to run and ride my bike. Science is fun.

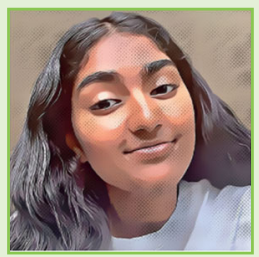

\section{SANDHYA, AGE: 15}

I am a sophomore in high school this year and am very excited to be in this program. I love learning about science and look forward to reading these articles. Fun Fact: I have a $100 \mathrm{lb}$ dog named Oreo!

\section{SANJANA, AGE: 14}

My name is Sanjana and I love to learn! Some of my hobbies include reading mystery books, watching movies, solving Rubix cubes, and biking. I hope to be a lawyer in the future and travel across the world! 

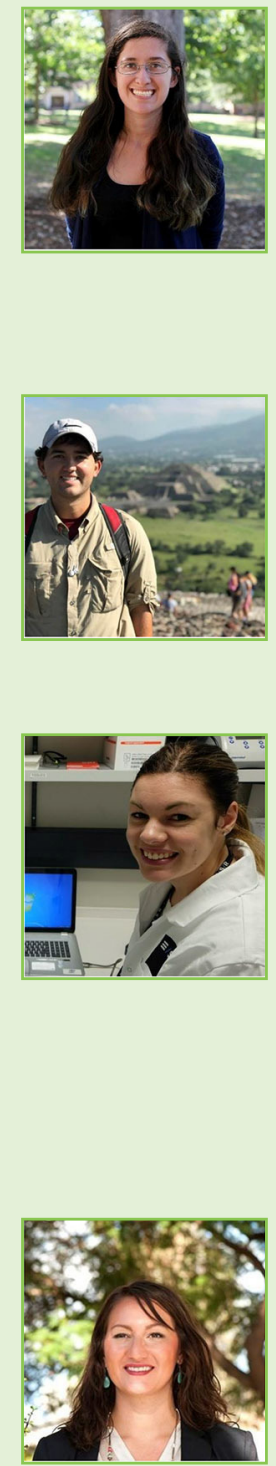

Abby is a second-year Ph.D. student at the Pennsylvania State University. She is an immigrant to the United States and has two siblings. She spends a lot of time looking at really old human skeletons to try to understand why different people had different chances of getting sick and dying in the past. Her favorite bone is the clavicle (the collarbone) and her favorite microorganism is $T$. palladium. *asg5573@psu.edu

\section{STERLING WRIGHT}

Sterling attends the Pennsylvania State University in State College, PA. As a Ph.D. student, he travels across the world studying the microorganisms and DNA in the dental plaque of people of different cultures. Because so many people suffer from cavities and periodontitis, he wants to find ways to improve oral health. When he is not working, he enjoys playing sports and playing music.

\section{NICOLE E. MOORE}

Nicole is a researcher and lab manager at Penn State University. She started her science journey in New Zealand, first using genetics to classify spiders, then researching viruses and viral communities that make humans and animals unwell. More recently, she joined the ancient DNA research area, first in Australia with Dr. Weyrich, and now in the United States. Her main focus is on how the microbiome changes and adapts over time in different cultures, and the ways we can study this change and improve it. Nicole enjoys playing sports and exploring the outdoors.

\section{LAURA S. WEYRICH}

Laura is an associate professor of anthropology at the Pennsylvania State University. After growing up on a farm in South Dakota, her love of medicine and the outdoors encouraged her to study microbiology and become a professor. She loves thinking about how microorganisms impact our daily lives-from tooth brushing, to baking bread, to growing plants-and understanding how and why microbiomes can be changed to improve our health. Her research typically uses a mix of modern medicine, ancient genomics, history, microbiology, and ethics. 